SH 221 A5 $1922 a$ 


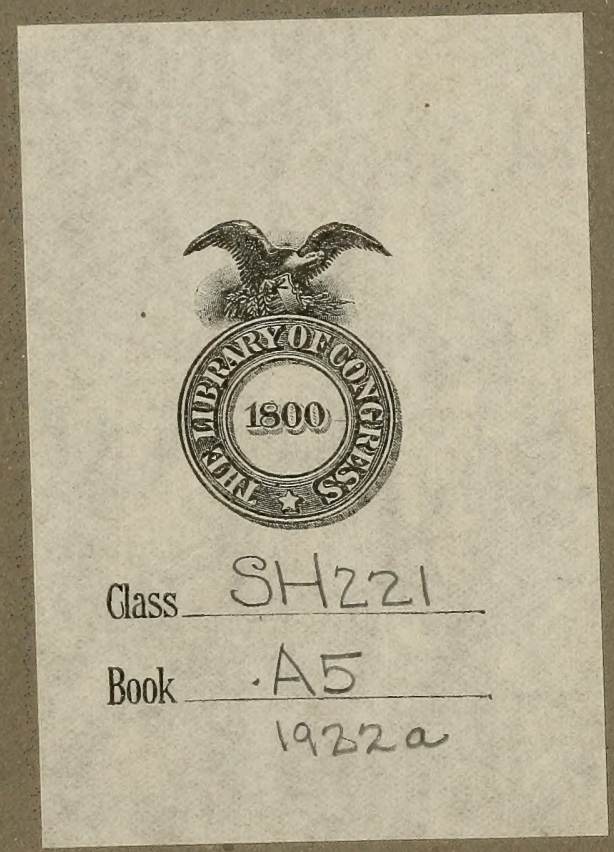




\section{MINISTERIO DE COMERCIO}

\section{LAS INDUSTRIAS DE PESCA DE LOS ESTADOS UNIDOS}

INFORME PREPARADO PARA

LA COMISIÓN DE LOS ESTADOS UNIDOS DE AMÉRICA EN LA EXPOSICION DEL CENTENARIO DEL BRASH

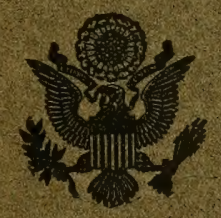

Para su Distribución en

La Exposición del Centenario del Brasil 1922-1923 


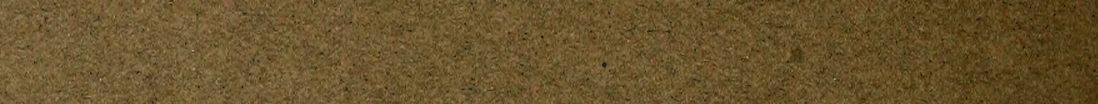

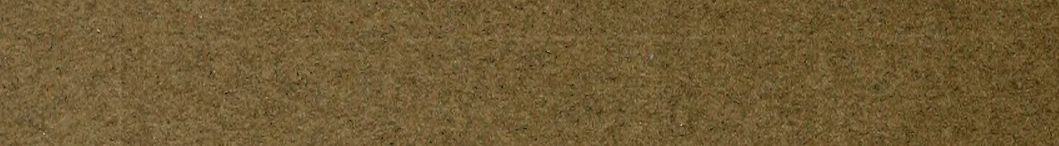
20.1.

(5)

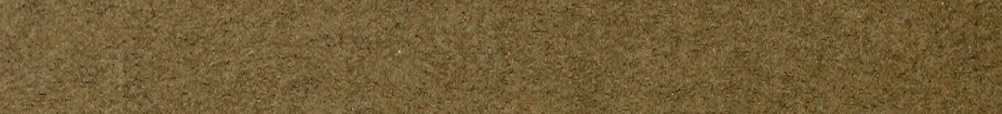

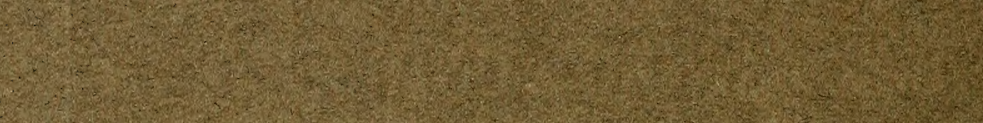

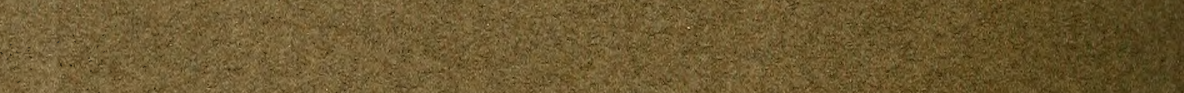

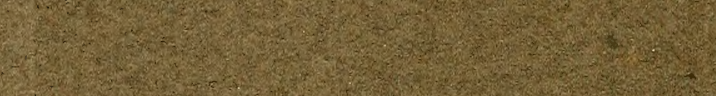

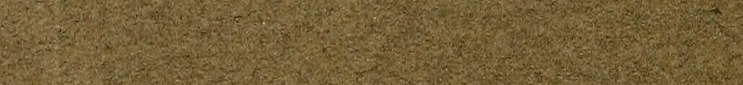

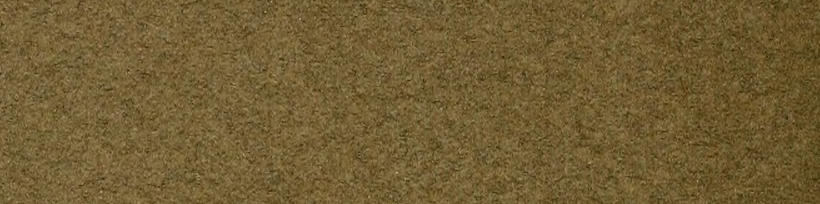

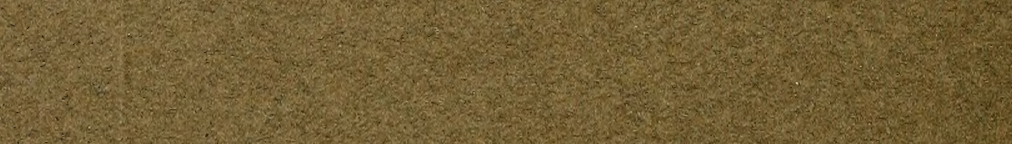

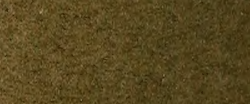

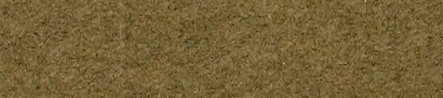

$x^{2}+2 x^{2}$

-

S.

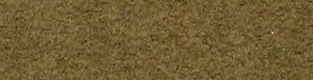

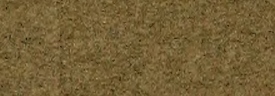




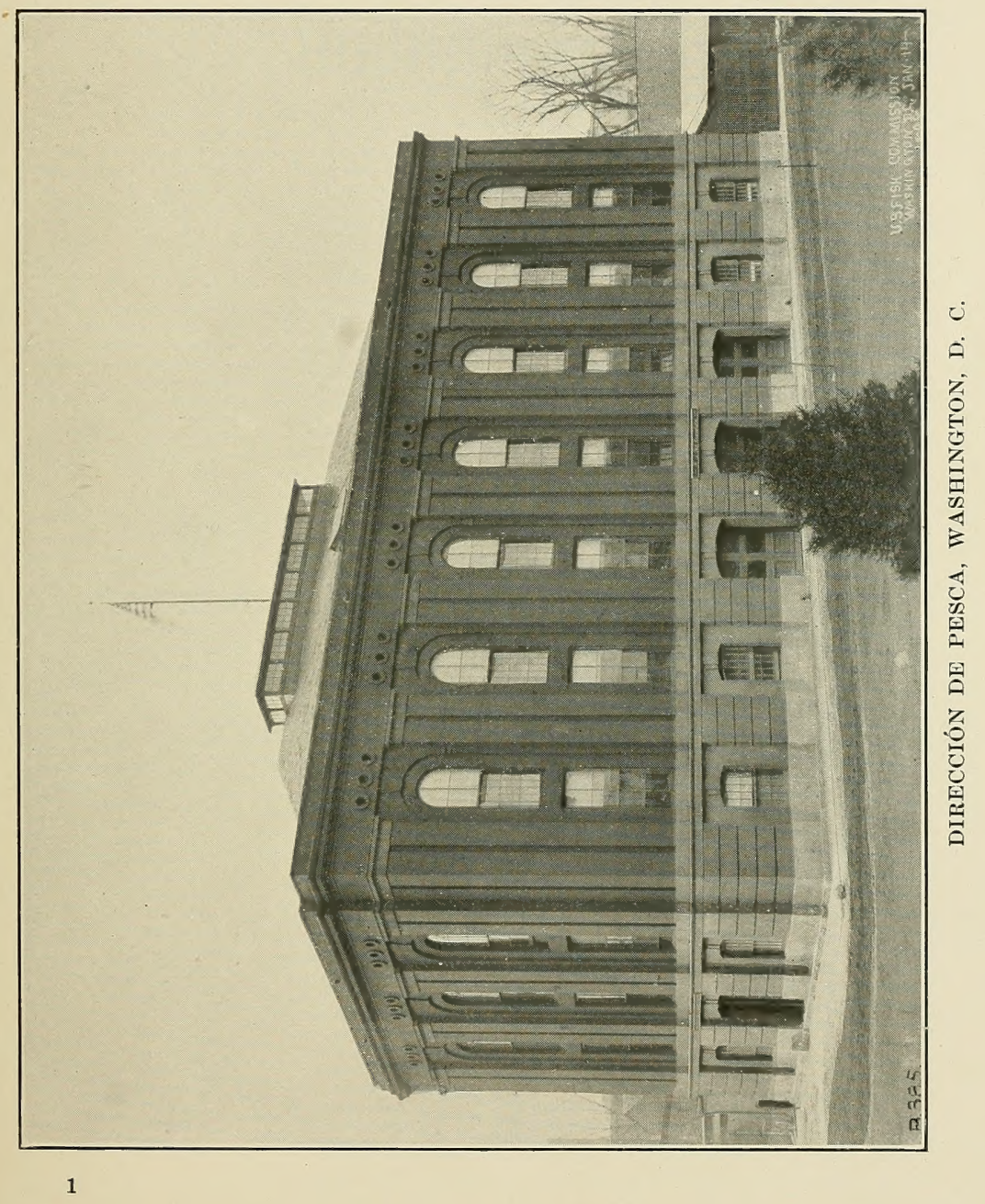





\title{
LAS INDUSTRIAS DE PESCA DE LOS ESTADOS UNIDOS
}

\author{
$\nabla$ \\ Suplementa la Exhibición \\ de la \\ OFICINA DE PESCA DE LOS ESTADOS UNIDOS \\ en la \\ EXPOSICIÓN DEL CENTENARIO DEL BRASIL \\ Rio de Janeiro, Brasil \\ 1922-1923 \\ $\nabla$ \\ Por
}

LEWIS RADCLIFFE

Asistente Encargado de la División de las Industrias de Pesca

Oficina de Pesca de los Estados Unidos 


$$
\begin{gathered}
5 H^{221} \\
A^{5} \\
1922 a
\end{gathered}
$$

LIBRARY OF COHENESS Recrives 


\section{LAS INDUSTRIAS DE PESCA DE LOS ESTADOS UNIDOS DE NORTE AMERICA.}

Es bien sabido que los Estados Unidos del Brasil tienen grandes cantidades de peces en sus aguas litorales y del interior y que sus habitantes realizan la importancia de desarrollar, en más grande escala, los recursos de la pesca, para mayor abundancia de comestibles en su patria. Con tal motivo los brasileños pueden tal vez interesarse en repasar este breve resumen de pesquerías, de un carácter tan importante en las artes y las industrias como lo son las de los Estados Unidos de Norte América, y en la relación existente entre esas industrias y la Oficina de Pesquerías norteamericanas. Sus estudiantes pueden enterarse de las oportunidades educativas que proporcionan nuestras escuelas de pesca y sus hombres de negocios de las posibilidades de obtener toda clase de equipos de pesca y artículos marinos, desde las redes hasta los productos preparados, los cuales pueden obtenerse convenientemente en los Estados Unidos de Norte América.

Desde el principio de nuestra historia las industrias de pesca han sido de la mayor importancia. Algunos de los primëros colonos, en muchas ocasiones, dependieron de la pesca como único médio de subsistencia. Las pesquerías han continuado siendo un factor muy importante en nuestro desarrollo industrial, como fuente de alime tación y para adiestrar los marinos para los tiempos de paz o de gutra. Actualmente hay en los Estados Unidos y en Alaska, como 200,000 personas dedicadas a la pesca, empleando cerca de 6,500 barcos de 50 más toneladas métricas de capacidad y 75,0oo lanchas para el acarreo y captación de los productos del mar y empleando redes y otros equipos y aparejos de pesca por valor de $\$$ I $5,000,000$.

El capital invertido en esta industria es aproximadamente de $\$$ I 70 ,000,000 y la pesca total llega a 2,500 millones de kilos, con un valor para los pescadores de $\$ 85,000$, ooo y mucho más de esta cantidad como productos ya preparados para el mercado.

De la pesca total, 68 por ciento es de productos marinos, 20 por ciento de especies anadromas y 12 por ciento de peces y otros productos de agua dulce. Los pescadores del Atlántico obtienen como 64 por ciento de la pesca total y los del litoral del Pacífico, Alaska y las aguas del país, como un 12 por ciento cada uno de esos grupos. 
ÁREAS DE PESCA.

Las áreas marinas más importantes son las de los bancos que se extienden de las costas orientales, desde Terranova a Massachusetts. Estos bancos ocupan un área como de 70,000 millas cuadradas donde se abastecen muy importantes pesquerías del bacalao, merluza, mero, pescadilla, merlango y otros peces. También en el litoral del Pacífico hay importantes bancos para la pesca, desde las costas de Oregón a las de Alaska que abastecen importantes pesquerías de mero, bacalao y otras especies. En las otras áreas de estas costas, los bancos son de menor importancia, sin embargo hay grandes pesquerías de mariscos como ostras, almejas, camarones, langostas, etc., en los ríos y algunos otros bajíos de los litorales, así como de peces anadromos como salmón, sábalo y arenque de río y peces de aguas superficiales como la caballa, tunas o sábalo y otras semejantes. De las aguas del interior del país, los Grandes Lagos, en su margen septentrional, son de mucha importancia, manteniendo muy valiosas industrias de pez blanco, arenque de lago, percas y carpas. Como una tercera parte de la pesca de las aguas interiores del país, provienen de esta región, siendo la pesca anual 50,000,000 de kilogramos.

\section{EQUIPOS Y APAREJOS DE PESCA.}

Distintas clases de redes, trampas y cercotes o atajadas, son los equipos más usados, representando un 45 por ciento de la inversión to.tal en aparejos de pesca de los Estados Unidos. Por lo general se usan atajadas fijas extendidas en aguas poco profundas (hasta de unos 15 metros de profundidad) y son empleados igualmente para los peces marinos, anadromos y de agua dulce. E1 distintivo característico de estas atajadas es una especie de cortina tegida que guía a los peces que ascienden los ríos o recorren las aguas litorales, a una especie de bolza o trampa.

Las redes de Jareta representan un 28 por ciento de la inversión en equipos de pesca. Estas pueden ser estacionarias o flotantes. Las redes barrederas tienen el tercer lugar en valor representando un 2 por ciento de la inversión y son empleadas para cercar los peces (redes de bolsa) o tirando de los extremos hacia la costa (variedad de arrastre. Las nazas y trampas para la langosta representan un 4 por ciento y los aparejos de anzuelos un 3 por ciento de la inversión. Muchos otros equipos tales como, fisgas, redes de todas clases, nazas, albareques, garfios, dragas, rastrillos, gafas, chinchorros, vargos, raños, tarrafas, así como todos los demás aparejos importantes, son empleados en las pescas en los Estados Unidos.

\section{PESQUERÍAS.}

Salmón.-La pesquería del salmón en el Pacífico puede considerarse comercialmente como la más importante de los Estados Unidos, su monto es como de I50,000,000 de kilogramos. Las cinco especies más importantes son las siguientes: 


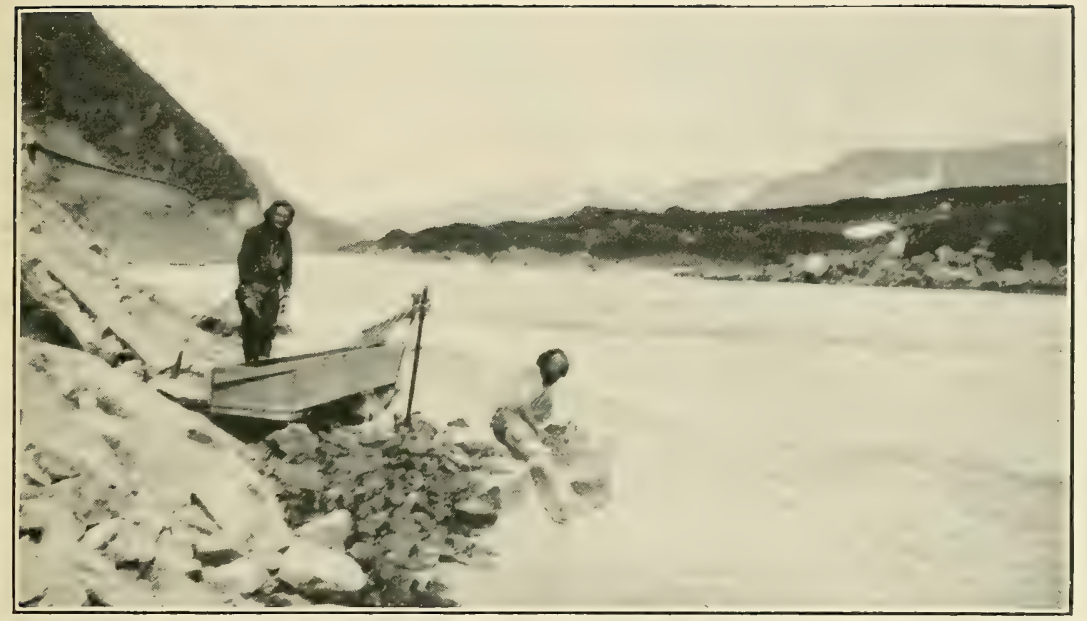

PESCANDO SALMÓN, CON RED, EN EL COPPER RIVER, ALISKA (METODO PRIMITIVO).

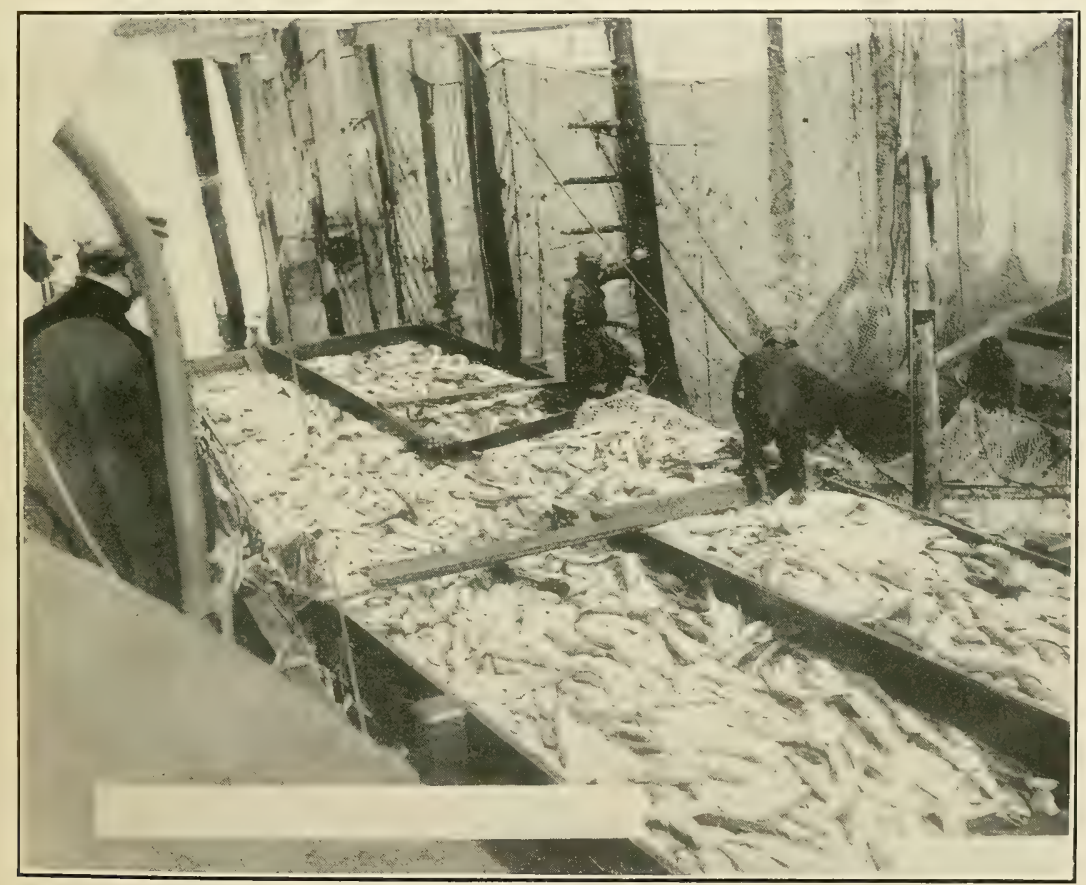

PESCA DE 36,000 SALMONES MEDIANTE UNA TRAMPA (METHODO MODERNO). 

"King" o "chinook" de carne de color, salmón oscuro, rojo o blanco.

"Bleau back" ("sockeye" o salmón rojo), carne roja (esta es la variedad de salmón que se enlata más en el mundo).

"Silver" (plateado) o salmón "coho," carne de excelente sabor, más palida que la del salmón rojo.

"Pink" (rosado) o "humpback," carne pálida y por consiguiente conocido en el mercado con el nombre de salmón "rosado."

"Chum," carne amarilla pálida.

Estos pescados son puestos en el mercado ya sea frescos, congelados, enlatados, secos en salmuera o ahumados. El método más generalizado de conservarlos es en lata. E1 valor anual ascien de a $\$ 30,000,000$ y se exporta a todos los países. Esta pesquería produce además I,500 toneladas de desperdicios y 300,00o litros de aceite de salmón.

Ostras.-No obstante que la pesca de ostras ha decaído en los últimos años sigue en importancia a la del salmón. El rendimiento anual actual es de unos 75,000,000 de kilogramos con un valor para los pescadores de

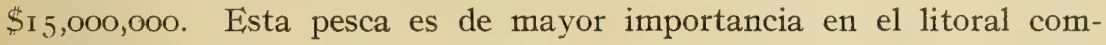
prendido entre los Estados de Rhode Island a Louisiana. Las ostras se envían al mercado frescas o en latas. El empaque en lata produce anualmente más de $\$ 2,000,000$. Las conchas son molidas y vendidas para estimulantes para las aves de corral o como abono calcáreo correctivo de las tierras ácidas. La producción de estos productos en I 92 I excedió de 259,000 toneladas.

Arenques.-Las principales pesquerías de las distintas variedades de arenques se encuentran en los Estados de Maine, California y en Alaska. En Maine las arenques de mar son pescados intensivamente para empacarlos en lata como sardinas. La pesca anual excede de 50,000,000 kilos. El valor de la pesca del arenque ha fluctuado en los últimos años entre 4 y 12 millones de dólares. En California la variedad "Pilcherd" es abundante y se emplea extensamente en lata, como sardina. El valor de la pesca es de 2 y medio a 3 y medio millones de dólares. En Alaska el arenque de río se conserva principalmente salado, incluyendo la conservación en salmuera según el procedimiento escocés. Esstas pesquerías rinden una cantidad considerable de abonos, harina de pescado y aceite.

Bacalao.-Las mejores pesquerías de bacalao se encuentran en las costas orientales de este país y en el Canadá, principalmente en los bancos. Varios millones de kilogramos de bacalao son pescados en las costas de Alaska anualmente y su rendimiento puede aumentar considerablemente. La pesca anual de bacalao excede de 45,000,00o kilogramos y es puesto al mercado, fresco, seco y salado, o ahumado.

Merluza.-La pesca anual de la merluza, desembarcada en su mayor parte en los puertos de pesca de Nueva Inglaterra, llega a cerca de 40,000,000 de kilogramos, el cual es puesto en el mercado ya sea fresco, salado, seco o ahumado.

Mero.-Anteriormente había pesquerías importantes en las costas de Canadá y Nueva Inglaterra, pero con la disminución de este pez, las 
pesquerías de mero se han trasladado casi todas a Alaska, y en los últimos años casi la totalidad de esta pesca ha provenido de esa región. La pesca anual en ambas costas es como 30,000,000 de kilogramos, los cuales se expenden en su mayor parte frescos o refrigerado.

Manhadden (pez del género "Breburtia," parecido al sábalo).--Este pez se encuentra en toda la costa del Atlántico y se pesca para la producción de desperdicios de pescado para abonos de tierras, para alimentar cerdos, ganado y aves de corral y para aceite de pescado que se emplea en la febricación del jabón, pinturas y otros varios artículos. Esta pesca excede a todas las demás que se obtienen en las aguas de los Estados Unidos, llegando hasta 450,000,000 de kilogramos anualmente.

Otras pesquerías de importancia son las de arenques de lago, en los Grandes Lagos, cuyo rendimiento anual es de 22,000,000 de kilogramos; el "week fish" (Cynoscóin regalis) que se encuentra en las playas del Atlántico cuya pesca llega a más de i 8,000,000 de kilogramos; el camarón en las costas de los Estados del Golfo de México, Atlántico del Sur, California y Alaska rinde aproximadamente 20,000,000 de kilogramos. Barbo o mujil.-La pesca en los Estados del Atlántico, al Sur y el Golfo llegan a r 8,000,000 de kilogramos. Cangrejos de los Estados del litoral medio del Atlántico rinden i 5,000,00o de kilogramos, y sábalo. originario del Atlántico y últimamente procreado en el Pacífico rinde ז 3,000,000 de kilogramos.

\section{MÉTODOS DE CONSERVARLOS.}

La fácil descomposición del pescado, las dificultades inherentes para venderlo vivo, la larga distancia entre las pesquerías y los lugares de consumo y la posibilidad de pescar, sólo en determinadas estaciones del año, son factores que han contribuído al desarrollo de excelentes métodos de conservación por medio del secamiento, salado, ahumado, en lata y refrigerado, así como un sinnúmero de variaciones a estos métodos fundamentales. El arte de conservar la pesca ha sido de gran importancia para el crecimiento de las industrias de pesca en los Estados Unidos.

\section{PESCADO FRESCO.}

Las enormes distancias entre las regiones de producción y de consumo en los Estados Unidos requieren que el pescado fresco sea sujeto a un método preservativo. Esto se efectúa empacando el pescado en barriles o cajas de madera y poniendo capas alternadas de hielo y pescado. Además, el transporte se hace en carros refrigerados. De esta manera grandes cantidades de pescado fresco son embarcadas a miles de kilómetros de distancia de los lugares de pesca.

\section{SECADO.}

E1 secado al aire libre, el método más antiguo de curar el pescado, es muy poco usado en los Estados Unidos. E1 clima no favorece este 
sistema de conservación. Un interés creciente se está manifestando en la posibilidad de preparar pescado seco y sus derivados por medio de maquinarias o estufas. Esto, sin embargo, no se ha logrado hacer en forma comercial.

\section{SALADO.}

Eil procedimiento de conservar pescado por medio de la sal es también muy antiguo y a la vez uno de los más sencillos y económicos, actualmente. Los métodos fundamentales son dos: empacar el pescado en sal seca o en salmuera. El llamado bacalao seco, merlango, merluza, pescadilla y otros parecidos, son en realidad pescados secados en sal y luego al aire libre en zarzos o en secadores especialmente construídos. Tales pescados se conservan muy bien, bajo condiciones climatológicas muy desfavorables y por consiguiente son extensamente distribuídos en todos los mercados del mundo.

La conservación en salmuera es comúnmente empleada con tales peces como la caballa, arenque, salmón, arenque de río y el mujil o barbo. Este es también un medio eficaz de conservar temporalmente el pescado para ahumarlo o someterlo después a otros procedimientos de conservación. El grado de conservación que se obtiene y las variaciones de este procedimiento son numerosos. En el caso del curamiento escxcés del arenque, el pescado se somete a salmuera en su propio jugo, lo cual le imparte un sabor muy especial. En el curamiento ligero del salmón pescado en clima templado, éste se efectúa parcialmente en una solución tenue de salmuera y luego se somete a refrigeración. Ninguno de estos procedimientos es adaptado a climas cálidos.

AHUMADO.

Los pescados ahumados pueden considerarse entre los más deliciosos alimentos, pero como este procedimiento no conserva el pescado al aire libre por mucho tiempo, su uso es muy localizado. Para ahumar el pescado es preferido el pescado aceitoso, como el arenque, salmón, arenque de río, esturión y pez blanco. De los pescados no muy aceitosos que se conservan ahumados, la merluza es la más importante. Para impartir el sabor ahumado y a la vez una permanente conservación, grandes cantidades de pescado están siendo empacados en latas después de haberlos sometidos al humo ligeramente.

EN LATA.

Este importante medio de conservación es extensamente empleado en los Estados Unidos, muy especialmente con el salmón, sardinas, tunas, camarones, ostras, almejas y cangrejos. En I $92 \mathrm{r}$, el valor de los productos conservados en lata excedió de $\$ 46$, ooo,ooo. 


\section{REFRIGERACIÓN.}

La congelación del pescado ccmo medio conservativo es muy empleada en tiempos de abundancia y precics bajos, para usarlo fresco en tiempos de escacés. Este métcdo de conservación es empleado en grande escala en los Estados Unidos. De 35 a 75 millones de kilogramos se congelan anualmente. Anteriormente se congelaba el pescado en contacto con el aire. Actualmente se muestra mucho interés por la posibilidad de congelarlo en salmuera.

\section{PRODUCTOS ACCESORIOS Y MISCELÁNEA.}

Ein los Eistados Unidos se emplean grandes cantidades de pescado de variedades inservibles como alimento, así como todos los residuos de la industria de la pesca. Estos se utilizan como un ingrediente para determinados abonos; harina de pescado para alimento de ganado; aceite para la fabricación de jabón y pinturas; para curar cueros, usos medicinales y lubricantes; goma de pescado, etc. Las pieles de tiburones y otros animales acuáticos se curten, obteniendo un excelente cuero. Las escamas de ciertos peces son empleadas en la preparación de "esencia de perla," para la fabricación de perlas artificiales. Las conchas de ostras y almejas son molidas para alimento de las aves de corral, abonos para tierras ácidas, construcción de caminos, etc. La concha de agua dulce es la base de la muy importante industria de los botones de concha. Las aletas del tiburón son disecadas para los mercados de los paíseș de Oriente. Varios otros productos accesorios de la pesca son utilizados en diversas artes e industrias. E1 valor de los productos de desperdicios en 1922 excedió de $\$ 8$,000,000 y el de los otros productos accesorios fué poco más o menos otro tanto.

\section{OFICINA DE PESQUERÍA DE LOS ESTADOS UNIDOS.}

El Congreso de los Estados Unidos pasó una ley, en 9 de febrero de 1871 , nombrando un encargado de Pesca y Pesquerías que investigara las causas y los hechos relacionados con una supuesta baja en la importancia y valor de la industria de pesca a fin de sugerir una medida correctiva. Este fué el principio del oportuno y antiguo movimiento de regularización que emprendió el Gobierno Federal.

Anterior a julio x de I903, la Comisión era independiente en su admi. nistración, dando parte directamente al Congreso y se le conocía con el nombre de Comisión de Pesca y Pesquerías de los Estados Unidos, pero al organizarse el Ministerio de Comercio fué incluído legalmente en ese nuevo departamento y la designación le fué cambiada por la que actualmente tiene. El proyecto primordial de la Oficina fué constituir un grupo de expertos para la investigación científica, estadística y práctica de la pesca, y esta fase del proyecto siempre ha subsistido prominentemente. Por medio de otra ley promulgada en junio so de 
I 872 se dió autorización para la propagación de peces comestibles, una rama del servicio que en la actualidad ocupa gran parte de las actividades de la Oficina. Sin poder administrativo o de acción, salvo los casos de la administración de las leyes correspondientes a la pesca en Alaska y a animales de pieles utilizables y de las pesquerías de la esponja en los mares de la costa de la Florida, la Oficina, actuando en calidad de consultora únicamente, ha podido ejercer una influencia decidida sobre las leyes de pesca de los diferentes Estados.

Está a cargo de la Oficina el Comisario de Pesca y Pesquerías y el Sub-Comisario y los trabajos están organizados en Divisiones, a cargo de un asistente cada una de ellas y en la forma siguiente:

División de Administración.-Essta División está encargada de la Oficina de Contabilidad, de las del Arquitecto e Ingeniero, de los barcos de propiedad de la Oficina, de la Biblioteca, Archivos, correspondencia y muebles y demás propiedades. Es responsable de las compras, reparaciones y sostenimiento de todos los barcos y lanchas y de todo lo que se relaciona con apropiaciones y propiedades.

División de Industrias de Pesca.-Las importantes funciones de esta División, en lo que toca a sus relaciones con las pesquerías comerciales, incluye lo siguiente:

(I) Estudios sobre la manera de conducir las operaciones de pesca con el objeto de efectuar mejoras y conocer los métodos destructivos o poco provechosos.

(2) Desarrollo de mejoras en los métodos de manejar, distribuir y poner al mercado, los productos de la pesca.

(3) Verificar investigaciones tecnológicas de los principios científicos que gobiernan la conservación de los productos de la pesca a fin de regularizar los métodos y efectuar mejoras y economía en las operaciones, desarrollar nuevos métodos y procurar que no se empleen aquellos que sean poco satisfactorios o antieconómicos en la práctica; mejorar los métodos de conservar los aparejos de pesca y asuntos semejantes.

(4) Obtener estadísticas de las pesquerías e industrias de pesca.

(5) Acrecentar los usos de los productos accesorios de pesca y encontrar empleo para aquellos que no son aun utilizados.

(6) Introducir los buenos métodos o procedimientos extranjeros de pesca, conservación y utilización de las pesquerías.

(7) Fomentar la demanda de peces comestibles y otros productos que son poco o nada apreciados en el mercado.

(8) Estudiar y desarrollar nuevas zonas de pesca y las pesquerías de las variedades antes desechadas.

Esta División tiene en Wáshington, D. C., un laboratorio de productos de pesca perfectamente bien equipado para conducir sus estudios tecnológicos. 
División de Piscicultura.-Esta División tiene a su cargo todo lo que se relaciona con la propagación artificial, distribución y cuidado de los peces. Sus trabajos efectivos en I92 I fueron llevados a cabo por conducto de 35 estaciones de cultivo de peces y 65 subestaciones y 5 carros de ferrocarril distribuidores de peces, con una capacidad en conjunto de 5 billones de peces y huevos. Aproximadamente 93 por ciento de esa cantidad fueron de las variedades comerciales más importantes o sea de salmón, sábalo, pez blanco, percas, trucha de lago, bacalao, pescadilla y lenguado.

División de investigaciones de peces comestibles.-Esta División se relaciona con todo lo concerniente a los problemas biológicos y bioquímicos y conservativos de las pesquerías que necesitan una prudente explotación, así como los medios y requisitos de mantenimiento o posible aumento de aprovisionamientos.

Estas investigaciones y experimentos son verificados en el Laboratorio en Wáshington, D. C., en dos estaciones biológico-marinas en las costas del Atlántico, una en el Golfo de México y otras de agua dulce en el Misisipí y estaciones ambulantes. Hay también un vapor equipado especialmente para las investigaciones a grandes profundidades marinas y otro para trabajos en las aguas litorales y varios pequeños barcos para los ríos y demás aguas del interior. Una fase importante de este trabajo es proporcionar consejo sobre hechos relacionados con la legislatura y administración de la pesca. Esta División también efectúa investigaciones y experimentos que tiendan directamente al aumento de las variedades de animales acuáticos, para usos comerciales, tales como las esponjas, ostras, almejas y tortugas.

Comisión de pesca y focas de piel fina en Alaska.-Esta Comisión está bajo el cargo inmediato del Comisario de Pesca y tiene dos importantes subdivisiones, a saber: la de focas y la de salmón. La de focas atiende todo lo relativo a la administración y mantenimiento de la pesca de la foca de piel fina en Alaska y al control de las islas Privilof, incluyendo la adquisición y preparación de las pieles de foca, una importante fuente de entradas para el Gobierno Federal. La de pesquerías de salmón tiene a su cargo hacer observar todo lo relativo a las leyes y prevenciones de la pesca de salmón y otros peces de Alaska; la inspección de pesquerías, fábricas de conservas alimenticias, saladeros y otros establecimientos de este género.

Los trabajos de la Oficina, muy especialmente los que se relacionan con el cultivo de peces, estan suplementados con los que efectúan las distintas comisiones de pesca y casa de los diferentes Estados.

Colegios de pesca.-Se proporcionan en dos de las Universidades de los Estados Unidos, o sean, las de la Universidad de Wáshington, Seattle, Wáshington, y Massachusetts Institute of Technology, Cambridge, Massachusetts, cursos para el adiestramiento de estudiantes que deseen seguir la 
profesión de pesca. Estos cursos incluyen las materias de Piscicultura, Biología y la parte comercial. Cornell University, Ithaca, Nueva York, proporcinona un curso en Piscicultura en conección con el Colegio de Agricultura.

Mercados americanos.-Las páginas que anteceden han revelado algo sobre la magnitud de la industria de pesca de los Estados Unidos. Para sostener esta industria los Esstados Unidos están ampliamente provistos de fábricas de cuerdas, hilo, maquinaria y útiles para empaque en latas, astilleros, equipos de refrigeración y almacenaje, aparejos y otros muchos requisitos de la pesca. Además, la producción de las pesquerías es de suficiente magnitud que permite la exportación en grande escala de los productos de pesca. 



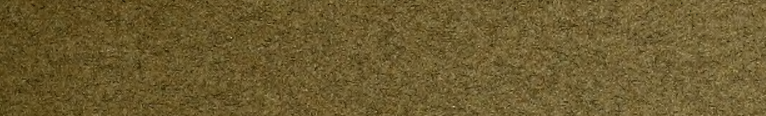

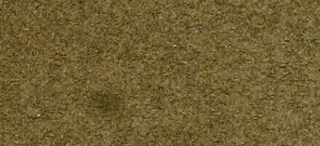

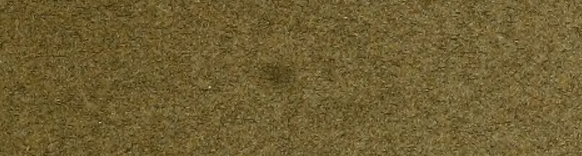

W.

2.

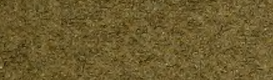

$\sin 20$

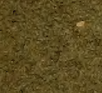

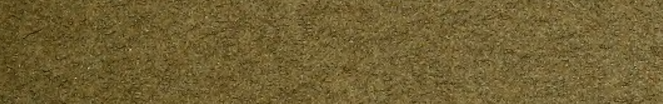

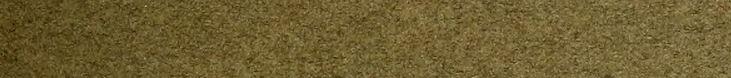

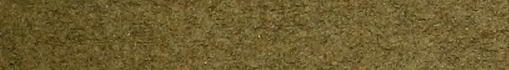

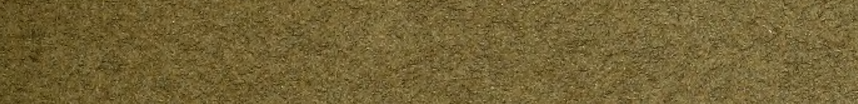

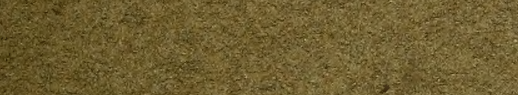

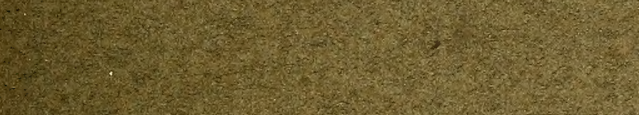

$\sin 20$

(6)

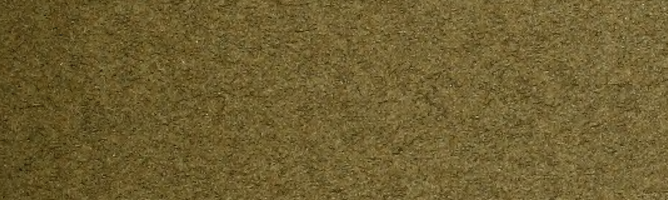

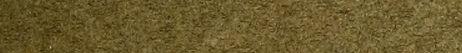

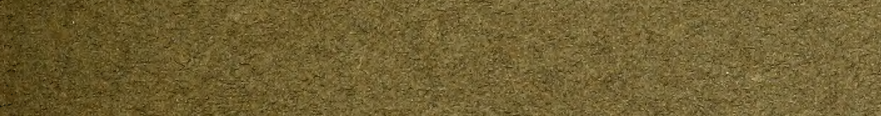

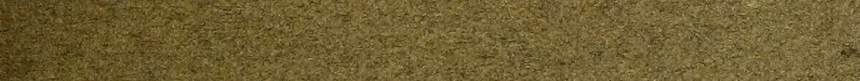

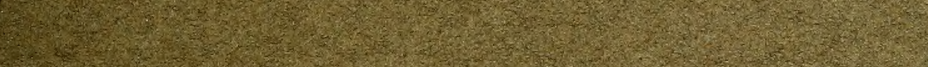

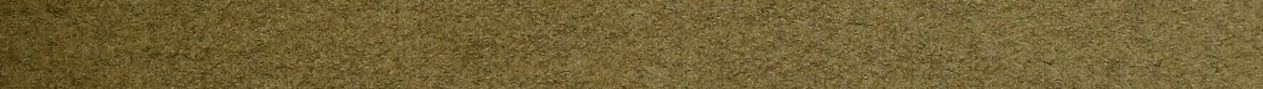

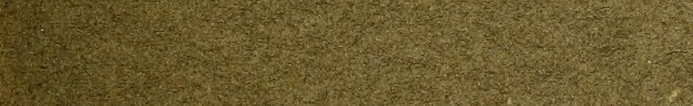

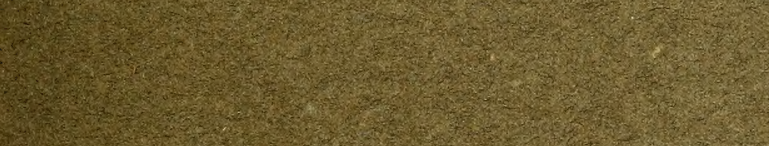

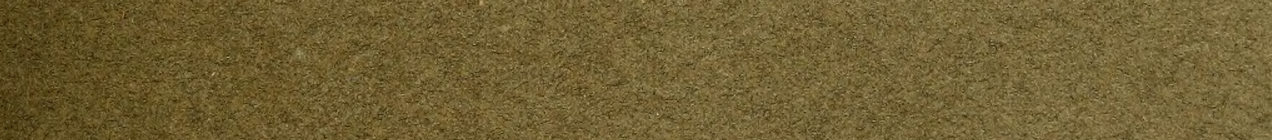

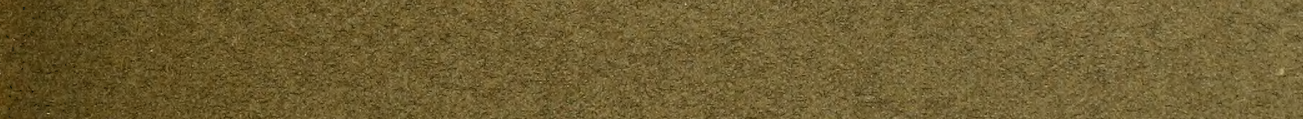

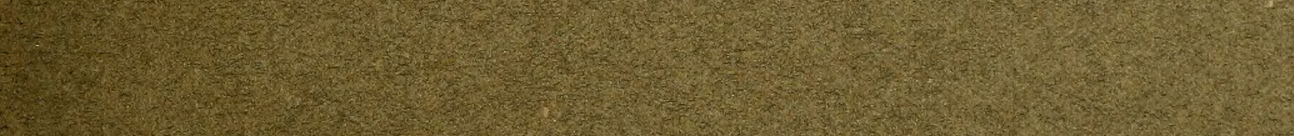
1)

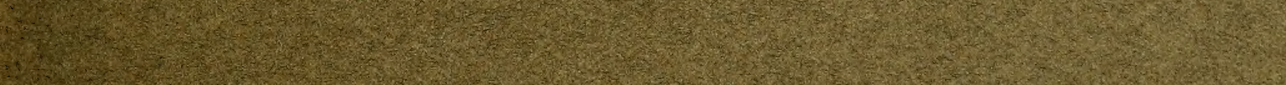
T.

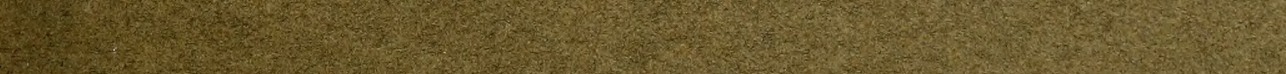

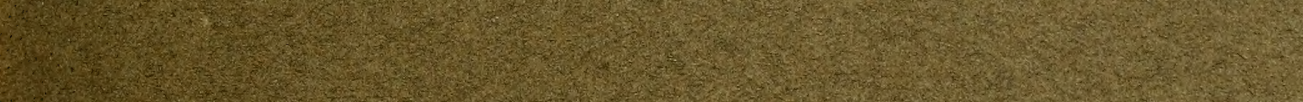

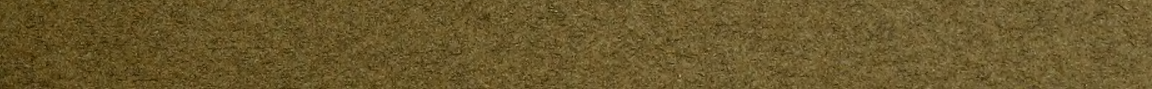


3.

r.

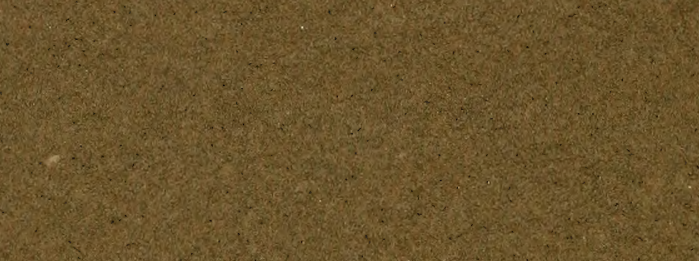




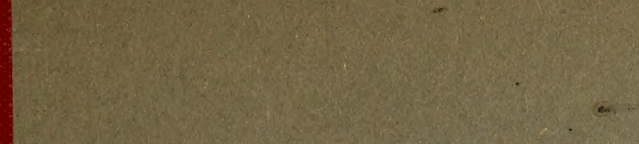

is 
